\title{
Estrada ecoeficiente: aplicação de asfalto com adição de composto madeira/borracha na região Norte do Brasil
}

\section{Eco-friendly road: rubber asphalt application in Northern Brazil}

Johnny Gilberto Moraes Coelho - Doutor em Engenharia de Recursos Naturais pela Universidade Federal do Pará (UFPA). Professor do Instituto Federal de Santa Catarina (IFSC).E-mail: johnny.coelho@ifsc.edu.br

João Guilherme Mota de Sousa - Doutor em Engenharia de Recursos Naturais pela Universidade Federal do Pará (UFPA). Professor da UFPA. E-mail: joao@ufpa.br

Carmen Gilda Barroso Tavares Dias - Doutora em Ciência e Engenharia dos Materiais pela Universidade Federal de São Carlos (UFSCAR). Professora da UFPA. E-mail:cgbtd@ufpa.br

\section{Resumo}

Materiais de engenharia, provindos de jazidas, vêm a cada dia perdendo espaço para materiais alternativos aplicados à indústria da construção. $\mathrm{O}$ impacto ambiental de desgaste do pavimento em condições normais é afetado pelo tipo e pelas porcentagens de materiais na mistura. Para mitigar os problemas de caráter ambiental causados pela extração de materiais de jazidas e pela destinação incorreta de descartes, empresas estão usando cada vez mais resíduo de pneu, conhecido como asfalto-borracha. O objetivo deste trabalho é ampliar o conhecimento quanto à aplicação de resíduos de construção em asfaltos assim como na produção de asfalto-borracha, diminuindo os problemas ambientais ocasionados pelo descarte de pneus em lugares inapropriados.

\section{Palavras-chave}

Ecoeficiência. Asfalto. Borracha de pneu. Resíduos sólidos.

\begin{abstract}
Engineering materials, coming from deposits, have been losing space every day to alternative materials, the construction industry. The environmental impact of pavement wear under normal conditions is affected by the type and percentages of materials in the mixture. To mitigate environmental problems due to the extraction of materials from deposits and incorrect disposal of waste, companies are increasingly using tire tires, known as rubber asphalt. The objective of this work is to increase knowledge about this application of construction waste in asphalts as well as to introduce a new technique for the production of rubber asphalts, thus reducing the environmental problems caused by waste tires discarded in inappropriate places.
\end{abstract}

\section{Keywords}

Eco-efficiency. Asphalt. Tire rubber. Solid waste. 


\section{INTRODUÇÃO}

O avanço urbano ocorre, em sua maioria, a partir de processos desorganizados e sem planejamento adequado para o desenvolvimento de sistemas que tenham capacidade estrutural para atender às demandas e às necessidades sociais de habitação e saneamento ambiental (BRAGA; GOUVEIA, 2020).

O asfalto é um derivado de petróleo de elevada viscosidade, com propriedades impermeabilizantes e adesivas, não voláteis, de cor preta ou marrom. É constituído basicamente por asfaltenos, resinas e hidrocarbonetos de natureza aromática, solúveis em tricloroetileno e obtidos por refinação de petróleo, podendo, também, ser encontrados na natureza como depósito natural (gilsonita) ou associados à matéria mineral (asfalto de Trinidad). O termo asfalto é, também, utilizado popularmente para denominar o conjunto de materiais aplicados na pavimentação, ou seja, a mistura constituída por um ligante asfáltico para pavimentação (cimento asfáltico de petróleo, asfaltos diluídos, asfalto modificado ou emulsões asfálticas) com agregados compostos por material mineral (PETROBRAS, 2015).

As usinas de asfalto mais modernas possuem um sistema computadorizado, aliado aos princípios básicos elementares de operação de usinas de asfalto a quente, garantindo alto índice de qualidade na produção de concreto asfáltico e evitando a degradação do meio ambiente (RAUBER; CASSANEGO; SILVA, 2004, p. 97).

Já o pneu, componente imprescindível ao funcionamento dos veículos, passou por muitas etapas desde sua origem, no século XIX, até atingir a tecnologia atual. A invenção do pneu remonta a mais de um século e possui fatos curiosos que até causaram a falência de alguns empresários. A borracha, por exemplo, não passava de uma goma utilizada para impermeabilizar tecidos e apresentava sério risco de se dissolver quando exposta a temperaturas elevadas.

Para mudar esse cenário, muitos experimentos iniciados pelo americano Charles Goodyear, por volta de 1830, confirmaram acidentalmente que a borracha natural exposta a altas temperaturas com enxofre mantinha suas condições de elasticidade. Estava descoberto o processo de vulcanização da borracha que, além de dar forma ao pneu, aumentou a segurança nas freadas e diminuiu as trepidações nos carros.

Alguns anos mais tarde, em 1845, os irmãos Michelin foram os primeiros a patentear o pneu para automóvel. As etapas iniciais de desenvolvimento dos pneus ainda passaram pelo feito do inglês Robert Thompson que, em 1847, colocou uma câmara cheia de ar dentro dos pneus de borracha maciça. A partir 
de 1888, com a utilização do pneu em larga escala, as fábricas passaram a investir mais em sua segurança.

Os pneus descartados na natureza constituem, nos países mais desenvolvidos e em muitos em via de desenvolvimento, um enorme passivo ambiental. Só no Brasil são produzidos cerca de 40 milhões de pneus por ano e quase metade dessa produção é descartada nesse período (GALLE et al., 2010).

O Projeto de Lei $n^{\circ}$ 1.500, de 22 de dezembro de 2007, em seu Art. 1, afirma que "todos os programas de asfaltamento e recapeamento e as rodovias estaduais devem ser pavimentadas ou recapeadas, quando se fizer necessário, com o chamado "asfalto-borracha", também chamado, asfalto ecológico" (SÃO PAULO, 2007).

Em 02 de agosto de 2010, foi sancionada a Lei $n^{\circ} 12.305$ que institui a Política Nacional de Resíduos Sólidos (PNRS), que dispõe sobre seus princípios, além de prever programas de prevenção e de redução da geração de resíduos. Tem como principal proposta a prática de hábitos de consumo sustentável e um conjunto de instrumentos que visam a propiciar o aumento da reciclagem e da reutilização dos resíduos sólidos (BRASIL, 2010). A lei regulamenta o destino adequado do lixo, seja ele proveniente do uso comum ou da indústria da construção civil, que também entra nesses parâmetros. No caso dos pneus inservíveis, é importante levar em consideração que uma legislação própria (BRASIL, 1998) já regulamentava seu descarte e sua destinação.

A utilização demasiada de embalagens plásticas, o seu descarte no meio ambiente e, consequentemente, as alterações na qualidade de vida da população causadas por esses descartes têm levantado muitas pesquisas e discussões, com a intenção de evitar um desequilíbrio ambiental.

A percepção ambiental pode vir a auxiliar o desenvolvimento socioeconômico e ambiental de um lugar, visando a uma boa qualidade de vida para a sociedade com integração ao meio ambiente.

O objetivo deste trabalho é ampliar o conhecimento quanto à aplicação de resíduos da construção em asfaltos, assim como inserir uma nova técnica para a produção de asfalto- borracha. Trata-se de uma proposta inovadora e mitigadora, bem como compensatória em relação à degradação gerada pela indústria da construção civil.

\section{TEORIA E METODOLOGIA APLICADA}

Nos países em desenvolvimento, os ecossistemas são bastante afetados pelos processos produtivos aliados à falta de planejamento urbano, o que tem 
favorecido a proliferação de graves problemas, tais como a favelização, a falta de infraestrutura, a violência, a poluição de todas as modalidades e o desemprego (LEÓN; ROBLES, 2002, p. 464).

No norte do Brasil, a construção civil necessita de uma melhor gestão dos materiais empregados, evitando, assim, quantias de matérias-primas num alto consumo de energia. Essa realidade pode ser mudada a partir da seletividade de insumos aplicados, por exemplo, nos novos pavimentos e na reabilitação dos pavimentos existentes. O impacto dos produtos utilizados na construção pode ser significativamente reduzido, promovendo a utilização das melhores técnicas disponíveis e de ecoinovação em plantas de produção, substituindo o uso de recursos naturais finitos por resíduos gerados em outros processos de produção, onde os localmente disponíveis fecham o ciclo de produção. Isso implica se comprometer de forma decisiva com a reutilização e a reciclagem e sempre minimizar o transporte de matérias-primas e produtos, promovendo a utilização dos recursos disponíveis em áreas locais.

O reaproveitamento de materiais de pavimentação no final da sua vida útil torna-se muito difícil e de elevado custo, devido à necessidade de separação dos vários tipos de materiais. A grande vantagem da reciclagem do pavimento asfáltico é que todo o material danificado pode ser completamente aproveitado, e o novo pavimento ainda pode receber um reforço extra durante a reciclagem, já que muitas vezes é realizada a aplicação de alguns materiais que funcionam como agentes estabilizadores - em geral, cimento, cal ou espuma de asfalto (BRIBIÁN; CAPILLA; USÓN, 2011, p. 1139).

O método de dimensionamento adotado pelo Departamento Nacional de Infraestrutura de Transportes (DNIT), denominado método do Engenheiro Murilo Lopes de Souza, foi retirado do Manual de Pavimentação (DNIT, 2006). $\mathrm{Na}$ região norte, tem-se limitado inicialmente a um ciclo de vida de 20 anos de durabilidade dos pavimentos flexíveis (SANTERO; HARVEY; HORVATH, 2011, p. 129). Nessa região, o principal entrave está na manutenção dos pavimentos asfálticos e na sua reestruturação com qualidade em desacordo com as normas técnicas brasileiras e estrangeiras.

Pavimentos asfálticos, ao serem construídos, podem ocasionar sérios riscos ao meio ambiente. Sendo assim, necessitam estar, tanto na fase de projeto quanto durante a execução, de acordo com os relatórios ambientais, Estudos e Relatório dos Impactos Ambientais (EIA/RIMA) para que, desta forma, atendam às exigências de municípios e estados. Um dos contaminantes são os produtos usados para fornecer maior resistência mecânica aos solos, como estabilizantes químicos e materiais de enchimento (fillers), os mais usuais na indústria da construção civil e 
em construção de pavimentos; esses podem, com o tempo e por meio do processo de lixiviação, serem contaminantes do solo (SHIH; MA, 2011, p. 1561).

Segundo o Projeto de Lei $\mathrm{n}^{\circ} 215$, de 2009, em seu Art. $1^{\circ}$, ficam instituídos o recolhimento e a destinação de pneus inservíveis da frota municipal de veículos de Manaus para a produção de asfalto-borracha. Segundo o Art. $4^{\circ}$, são propósitos da adição de borracha oriunda de pneus usados em misturas betuminosas para a pavimentação urbana: minimizar o problema da disposição de pneus usados, ampliando a vida útil do aterro sanitário de Manaus; eliminar o lançamento de materiais ambientalmente nocivos, causadores de poluição cênica, residual e que propiciam a proliferação de vetores de doenças; e melhorar o desempenho dos pavimentos urbanos, reduzindo os custos com obras de reparos no revestimento das vias urbanas (AMAZONAS, 2003). Essa técnica, que utiliza borracha proveniente de pneus usados em asfaltos, tem resultados positivos e, para sua implantação efetiva na região norte, necessitaria de uma maior ação do poder público para o incentivo desse procedimento, sendo assim uma benfeitoria à população (ALMEIDA; MENDES; LIMA, 2018).

Mais recentemente, a Lei $n^{\circ} 18.145$, de 2021, em seu Art. $1^{\circ}$, preconiza que, na pavimentação asfáltica ou na conservação das estradas do estado e das vias municipais, deve-se dar preferência à massa asfáltica adicionada com borracha de pneus inservíveis, denominada asfalto-borracha ou asfalto ecológico, nas situações recomendadas pela área técnica (SANTA CATARINA, 2021).

Outros materiais também podem ser inseridos ao ligante asfáltico, como o polímero tipo polietileno reciclado de resíduos de embalagem que substitui os modificadores de polímeros comuns, e podem modificar o asfalto. Em Coelho, Mesquita e Dias (2020), outro resíduo que está sendo usado em revestimentos asfálticos são a madeira e a borracha reciclada de pneu para o ganho de flexibilidade e resistência de asfaltos, teste experimental feito em rodovias no estado do Amapá. Os asfaltos tendem a melhorar em alguns aspectos com esses resíduos, como na ductilidade e no ponto de amolecimento (GOU et al., 2020). As fibras de polipropileno melhoram os aspectos físicos e mecânicos dos asfaltos aplicados em campo (FANG; LI; ZHANG; WANG, 2008, p. 1186), assim como o aumento nos valores de estabilidade e nos valores de quociente de Marshall, indicando a pseudorrigidez de asfaltos (TAPKIN; ÇEVIK; UŞAR, 2010, p. 4660).

Sobre o aproveitamento de resíduos de madeira, atualmente, o Pará é o estado que mais explora madeira no Brasil. Além disso, é importante destacar que toda essa atividade, investimento e transformação ocorrem quase que de forma aleatória. A indústria responde às forças do mercado, com a meta clássica de qualquer empresa: maximizar lucros em curto prazo. Não há visão clara dos 
custos e benefícios dessa atividade e falta, acima de tudo, uma reflexão sobre como racionalizar e dividir danos e custos que a atividade madeireira traz (STRAND et al., 2018, p. 662).

A madeira é um dos produtos de maior destaque na pauta de exportação paraense, ocupando o terceiro lugar no ranking de produtos exportados. O aumento da eficiência do processo industrial da madeira também teria efeito direto na quantidade da área florestada necessária para manter os atuais níveis de produção (FEARNSIDE; GRAÇA, 2009, p. 44). Por exemplo, apenas 35\% de cada tora é transformada em produto serrado, mas essa eficiência poderia ser aumentada para 55\% através de melhoramento simples na manutenção de máquinas e no treinamento de mão de obra.

De acordo com esses dados, $65 \%$ das toras são desperdiçadas, transformandose em resíduos não aproveitados pela indústria. As empresas que tratam diretamente desse resíduo sólido são as responsáveis pela sua extração e destinação final, mitigando os impactos ambientais da indústria no setor (PEREIRA; CARVALHO; PINTO, 2010; FAGUNDES; HASELEIN; BONIN, 2006).

O termo resíduo de madeira, por muitas vezes, é associado à palavra problema, pois geralmente sua disposição ou utilização adequada gera custos altos que, muitas vezes, se quer evitar no que tange a carga tributária incidente sobre os produtos florestais madeireiros (MORAES; SOLA, 2019, p. 171). Porém, o conhecimento da quantidade, da qualidade e das possibilidades de uso desse material pode gerar uma alternativa de uso que viabilize o seu manuseio (SÃO GONÇALO, 2017).

O principal problema dos resíduos da construção civil (RCC) produzidos, do ponto de vista ambiental e até estético, é o seu depósito irregular, incentivando a criação de pontos de lixo. Por outro lado, do ponto de vista financeiro, esse descarte irregular onera as administrações municipais, que acabam tendo de se responsabilizar pela remoção e disposição desses resíduos acumulados. Para tornar-se sustentável do ponto de vista ambiental e econômico, a construção deve estar baseada na prevenção e na redução dos resíduos gerados, o que pode ser obtido com a aplicação de metodologias de Produção Limpa durante todo o processo de construção e vida útil de uma edificação (AZEVEDO; KIPERSTOK; MORAES, 2006, p. 66; SOUZA et al., 2004, p. 34; DEBONI et al., 2020).

Uma solução, que a cada dia ganha força entre os pesquisadores, é a reciclagem de RCC e sua reutilização na própria construção civil, como matéria-prima alternativa (SANTOS; TUBINO, 2021). Além da redução da superexploração de jazidas minerais para extração de recursos naturais não 
renováveis, há também a carência de locais para a deposição desses resíduos, fazendo com que as distâncias entre os locais de demolição e as áreas de disposição sejam cada vez maiores, onerando os custos de transporte (FRANCO et al., 2021). A reciclagem de RCC contribui também para a ampliação da vida útil dos aterros, especialmente em grandes cidades, em que a construção civil é intensa e há escassez de área para depósito (BRASILEIRO; MATOS, 2015; PIOVEZAN JÚNIOR, 2007).

Vale destacar que a mobilização social é fundamental para a implantação do sistema de logística reversa na construção civil. A reflexão sobre as práticas sociais, em um contexto marcado pela degradação permanente do meio ambiente e do seu ecossistema, envolve uma necessária articulação com a produção de sentidos sobre a educação ambiental (HAMMES et al., 2020). A dimensão ambiental configura-se crescentemente como uma questão que envolve um conjunto de atores do universo educativo, potencializando o engajamento dos diversos sistemas de conhecimento, a capacitação de profissionais e a comunidade universitária numa perspectiva interdisciplinar (MARTIN et al., 2021).

Nesse sentido, a produção de conhecimento deve necessariamente contemplar as inter-relações do meio natural com o social, incluindo a análise dos determinantes do processo, o papel dos diversos atores envolvidos e as formas de organização social que aumentam o poder das ações alternativas de um novo desenvolvimento, numa perspectiva que priorize um novo perfil de desenvolvimento, com ênfase na sustentabilidade socioambiental (JACOBI, 2003; VITORINO et al., 2010, p. 10).

A aplicação de tecnologias ambientais amigáveis, as tecnologias emergentes relacionadas à gestão de informações, como sistemas de código de barras, sistema de posicionamento global (global positioning system - GPS), simulação de sistemas de comércio eletrônico e sistemas de informações geográficas (GIS), estão sendo adotadas para a construção civil. São usadas para facilitar atividades relacionadas ao projeto, como coordenação e comunicação de projetos, e para fornecer informações quantitativas de um projeto predeterminado como entrada para análise de resíduos de materiais, com o objetivo de reduzir o desperdício na construção (OLIVEIRA, et al. 2020; BOSDOGIANNI, 2007).

A metodologia utilizada pelos autores é baseada nas normas do DNIT, do Manual de Pavimentação (DNIT, 2006), para construção de pavimentos com a incorporação de borracha reciclada de pneus em pista. As misturas são um concreto asfáltico do tipo a quente, enquadrado na faixa $\mathrm{C}$ do DNIT, e do tipo asfalto-borracha pelo processo seco; a diferença entre elas está na granulometria da borracha utilizada. Para caracterização dos materiais, foi realizada a análise 
granulométrica, utilizando o método das peneiras, conforme recomendações da norma DNER-ME 083/98 (DNER, 1998). Também foi realizada a análise da densidade dos agregados e da borracha.

\section{RESÍDUOS GERADOS NA CONSTRUÇÃO CIVIL}

Segundo Paixão e Silva (2019), ao longo da história, o homem vem explorando de forma inadequada os recursos naturais para produzir os mais diversos tipos de materiais. Essa exploração vem aumentando cada vez mais devido ao grande crescimento populacional urbano, a intensa industrialização e o aumento do poder aquisitivo da população em geral. Devido a esses fatores, estão ocorrendo grandes alterações no meio ambiente, as quais vêm comprometendo negativamente a qualidade do solo, do ar e dos recursos hídricos.

A construção civil é reconhecida como uma das mais importantes atividades para o desenvolvimento econômico e social do país. Porém, é uma grande geradora de impactos ambientais devido ao grande consumo de matériaprima, à modificação da paisagem e à grande geração de resíduos, considerandose: que os RCC representam um significativo percentual dos resíduos sólidos produzidos nas áreas urbanas dos municípios (KARPINSKI et al., 2008, p. 86); a viabilidade técnica e econômica de produção e o uso de materiais provenientes da reutilização, reciclagem e beneficiamento desses resíduos; a necessidade urgente de que, nos municípios do norte do país, seja concedido um sistema de gestão integrada de resíduos sólidos urbanos, que proporcione benefícios de ordem social, econômica e ambiental. Foram estabelecidas, assim, essas diretrizes preconizadas na Resolução 307 do Conselho Nacional de Meio Ambiente (BRASIL, 2002).

A geração dos RCC está intimamente ligada com a parcela do excesso de consumo de materiais nos canteiros de obras. Esse desperdício de material é entendido como a percentagem entre a quantidade de material teoricamente necessário (QMT) e a quantidade de material realmente utilizado (QMR), ou seja, perda em $\%$.

O descarte de resíduos sólidos pode ser feito de três maneiras distintas: furto ou extravio, incorporação de materiais à edificação e despejo na natureza de forma inadequada, conhecido como entulho (SOUZA et al., 2004, p. 36). Comparando, o descarte no meio em que vivemos tanto dos resíduos domiciliares (matéria orgânica) quanto dos resíduos do tipo resíduos sólidos urbanos (RSU) acabam equivalendo-se em porcentagem, a exemplo do Brasil (Figura 1). 
Figura 1 - Gravimetria dos RSU no Brasil

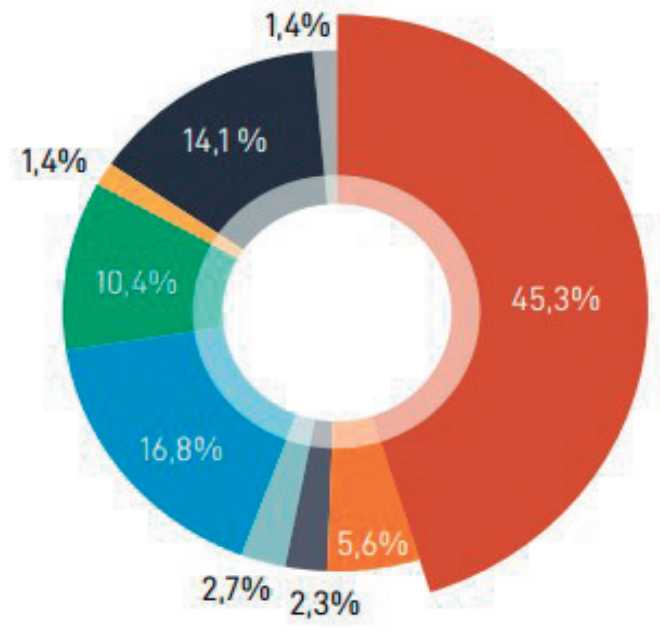

Matéria orgânica

Têxteis, couros e borracha

Metais

Vidro

Plástico

Papel e papelão

Embalagens multicamadas

Rejeitos

Outros

Fonte: ABRELPE (2020).

É possível observar elevado percentual de materiais recuperáveis descartados no meio ambiente que podem retornar ao ciclo produtivo, gerando bons impactos econômicos e sociais (BOSDOGIANNI, 2007; CICLOSOFT, 2008). Na Figura 2, destacam-se 3.152 municípios que, em 2010, registravam alguma iniciativa de coleta seletiva, enquanto na década seguinte esse número aumentou para 4.070 municípios. Importante destacar, porém, que em muitos municípios as atividades de coleta seletiva ainda não abrangem a totalidade de sua área urbana (ABRELPE, 2020).

Figura 2 - Distribuição dos municípios com iniciativas de coleta seletiva em \%

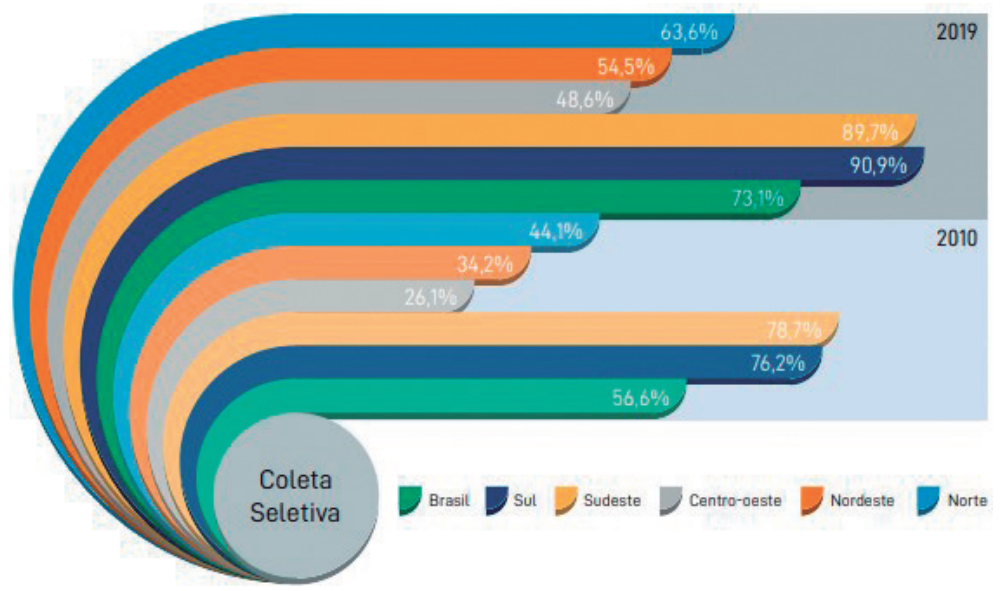

Fonte: ABRELPE (2020). 
Em alguns municípios brasileiros, mais de 75\% dos resíduos da construção civil são provenientes de construções informais (obras não licenciadas), enquanto $15 \%$ a $30 \%$ são oriundos de obras formais (licenciadas pelo poder público) (PINTO, 2005; PINTO; GONZÁLES, 2005). No mundo, aproximadamente 2,01 bilhões de toneladas de RSU são geradas anualmente e espera-se que, em 2050, esse número chegue a 3,40 bilhões de toneladas, um aumento de quase $70 \%$. Para minimizar esse impacto, alguns países (Figura 3) buscam usar tecnologia e inovação, tendo o tratamento como prioridade na gestão (KAZA et al., 2018).

Figura 3 - Quantificação em massa dos RCC no Brasil

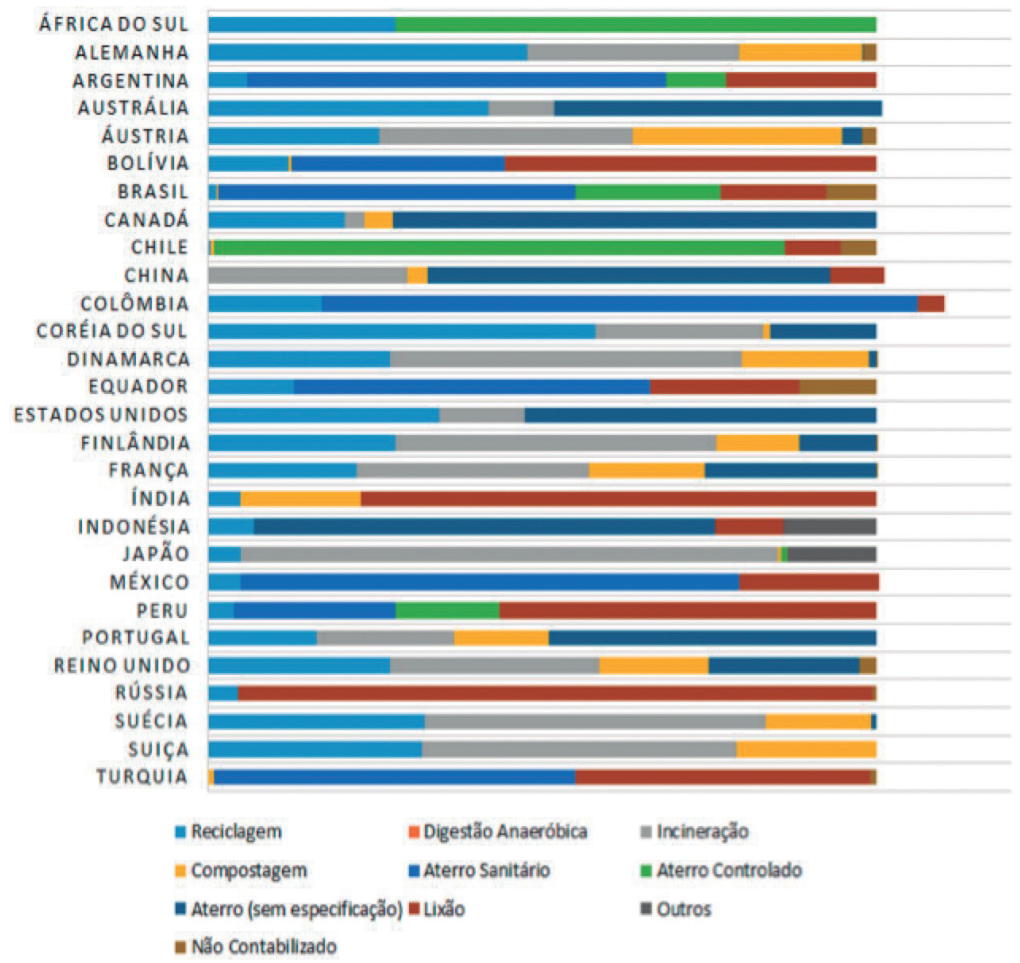

Fonte: Kaza et al. (2018).

A partir desse panorama, nota-se a necessidade de uma gestão dos resíduos gerados em grandes e pequenas obras, reformas e reparos de pavimentação, demolição e construção, o que é imprescindível para o desenvolvimento sustentável da sociedade. O correto manuseio e gerenciamento de resíduos na construção civil não só diminui os índices de desperdício e os gastos com materiais, mas também cumpre papel ecológico e sustentável (SOUZA et al., 2004, p. 44). 


\section{ASFALTOS ECOLÓGICOS}

O impacto ambiental de desgaste do pavimento em condições normais não é grandemente afetado pelo tipo de mistura ou pelo volume de mistura, mas sim por fluidos de água e de materiais perigosos. Embora as interações químicas permaneçam na água, combustíveis causam enfraquecimento da massa asfáltica misturada a quente (SANTANA et al., 2018). Tais efeitos são refletidos em grandes variações na susceptibilidade de asfaltos misturados a quente depois de aplicados. Por fim, na presença de água e, especialmente, materiais perigosos, tradicionais, em misturas densas têm um impacto ambiental sensivelmente inferior ao de misturas porosas europeias (PRATICÒ; AMMENDOLA; MORO, 2010, p. 127).

Os pavimentos rodoviários sofrem deterioração devido à ação do tráfego ao longo do seu uso e das intempéries, surgindo a necessidade de recuperálos ou reabilitá-los. A reciclagem de pavimento tem conquistado os órgãos governamentais e ambientalistas por ser uma opção economicamente viável, além de ser diplomaticamente correta e viabilizar o reaproveitamento parcial dos elementos, possibilitando menor extração de recursos naturais, diminuição dos gastos de energia e minimização dos impactos ambientais (ARAVIND; DAS, 2007, p. 935; BRUGNOLI; NASCIMENTO; MARQUES, 2018).

As pesquisas começam a apontar significativas mudanças nas condições climáticas e prever a escassez de recursos naturais, por isso tornou-se preocupação a nível mundial reduzir os impactos causados pelo homem ao ambiente. Diante desse cenário, o setor da construção civil, que consome grande quantidade de recursos naturais e é gerador potencial de resíduos, não se abstém das preocupações ambientais. Isso justifica o interesse dos pesquisadores em desenvolver materiais alternativos, assim como reaproveitar resíduos para a construção. Dentre os que vêm sendo estudados, cita-se as garrafas de Polietileno Tereftalato (PET). A indústria de líquidos cada vez mais opta pelo uso de garrafas plásticas para o armazenamento de seus produtos, devido à segurança e à eficiência que o material oferece. Por essa razão e pela tendência da sociedade de aumentar o consumo desses produtos, o destino correto para essa quantidade de resíduos plásticos é de grande preocupação (SERRA et al., 2018). A incorporação de polietileno reciclado (PEAD) no ligante asfáltico fornece maior resistência à deformação permanente devido à sua alta estabilidade e gera valores maiores de módulo de resiliência a temperatura de $25^{\circ} \mathrm{C}$ (FANG; LI; ZHANG; WANG, 2008, p. 1187). 
Obtido a partir da combinação entre pó de borracha de pneus e ligante asfáltico, o asfalto ecológico é considerado uma boa alternativa para conciliar o desenvolvimento urbano com a preservação ambiental. Trata-se de um produto classificado como sustentável, uma vez que contribui para a redução da utilização de matérias-primas não renováveis.

O asfalto-borracha é um revestimento de pavimento constituído de cerca de 14\% de pó de pneu moído. É indicado para revestir pavimentos de rodovias e vias de cidades com volumes de tráfego moderado, alto e muito pesado, além de ser mais durável que o asfalto convencional.

O uso de resíduos de madeira em pavimentos asfálticos ainda não é comum, mas é atribuído ao ganho de resistência estrutural e à reutilização desse material descartado na natureza. Segundo Coelho, Mesquita e Dias (2020), os resultados mostraram que o resíduo de madeira dura é compatível com a borracha e eficiente nas propriedades reológicas quando misturado ao cimento asfáltico de petróleo.

\section{INCORPORAÇÃO DE BORRACHA DE PNEUS E MADEIRA RECICLADA: UM EXEMPLO NO MUNICÍPIO DE MACAPÁ-AP}

O composto madeira/borracha foi ensacado, armazenado em laboratório e, posteriormente, foi inserido na correia transportadora da usina de asfalto móvel para mistura com cimento asfáltico de petróleo (CAP 50/70) e os agregados via seca. A madeira/borracha é introduzida diretamente no misturador da usina de asfalto. Depois de processado em usina gravimétrica móvel (mistura dos agregados pó de pedra, brita 0 , madeira/borracha), o material foi transportado para o local da pavimentação.

Desta forma, o trecho com concreto asfáltico convencional foi executado. Foram quatro etapas para a pavimentação (DNIT, 2006): confecção do composto no laboratório de mecânica dos solos do Instituto Federal do Amapá (Figura 4); mistura asfáltica por meio de usina móvel localizada no município de SantanaAP (Figura 5); transporte do material em estudo; e pavimentação em concreto asfáltico convencional e modificado (Figura 6). 
Figura 4 - Fluxograma da confecção do composto madeira/borracha

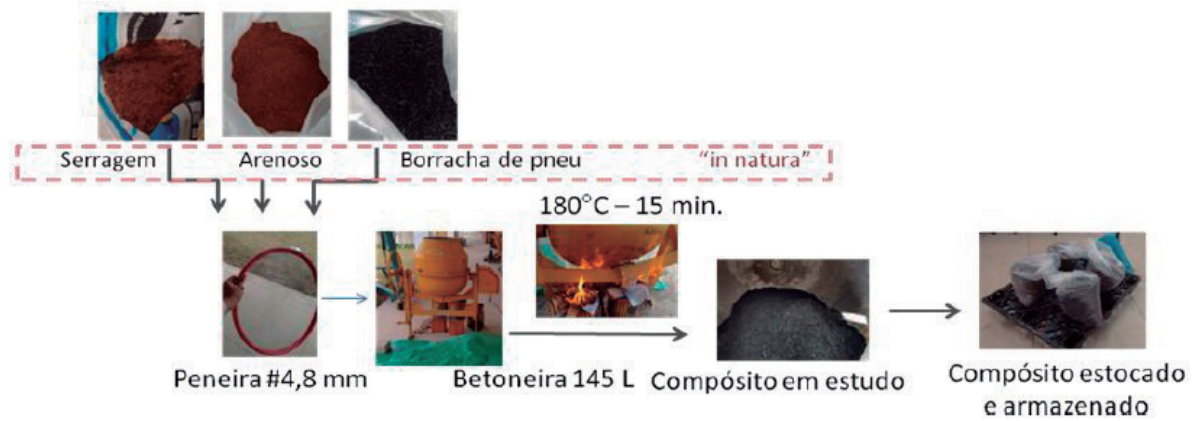

Fonte: elaborado pelos autores, 2021.

Figura 5 - Mistura asfáltica de asfalto com composto madeira/borracha

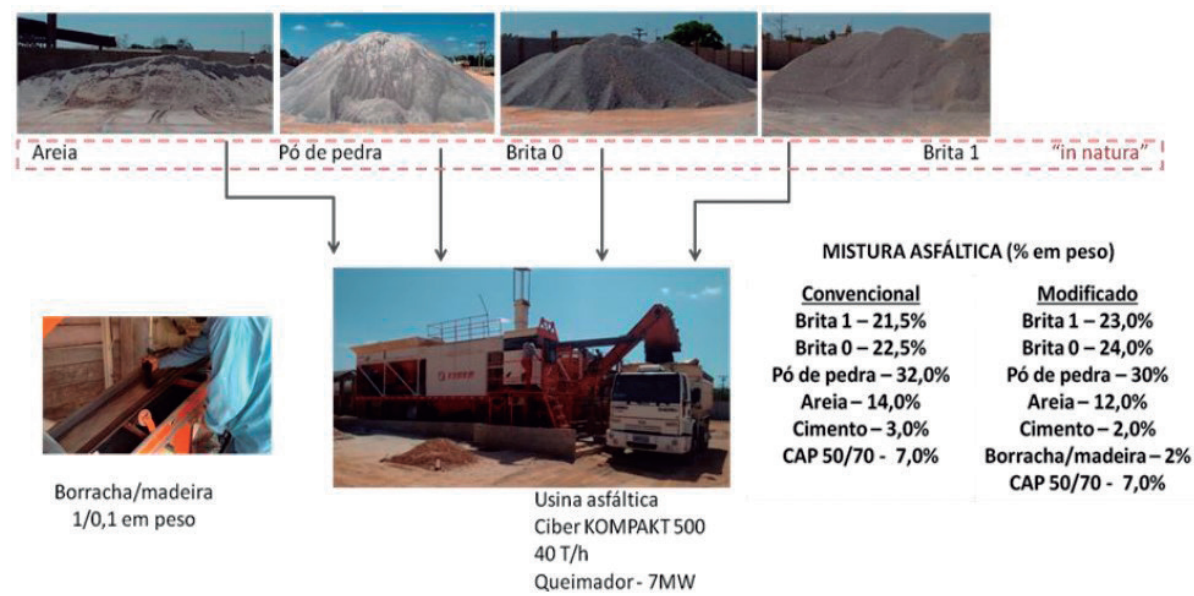

Fonte: elaborado pelos autores, 2021.

Figura 6 - Pavimentação de trecho urbano com asfalto convencional e modificado
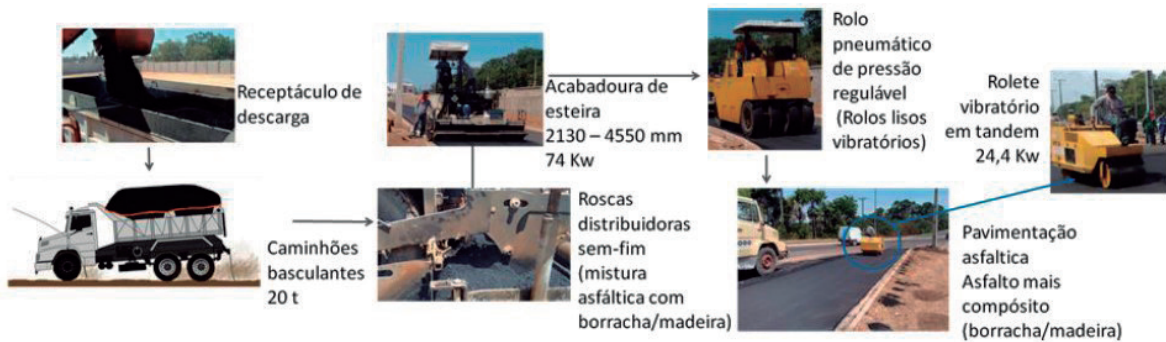

Fonte: elaborado pelos autores, 2021. 
O asfalto modificado já está aplicado há 50 meses, em contínuo uso, no conjunto condominial em estudo, localizado na Rodovia Juscelino Kubitscheck, Km 05, Jardim Equatorial, Macapá-AP, Brasil. Ele vem sendo acompanhado durante o período de uso, como mostra a Figura 7, que reúne as imagens locais durante os respectivos meses de estudo.

Figura 7 - Gerenciamento do pavimento em estudo durante 50 meses
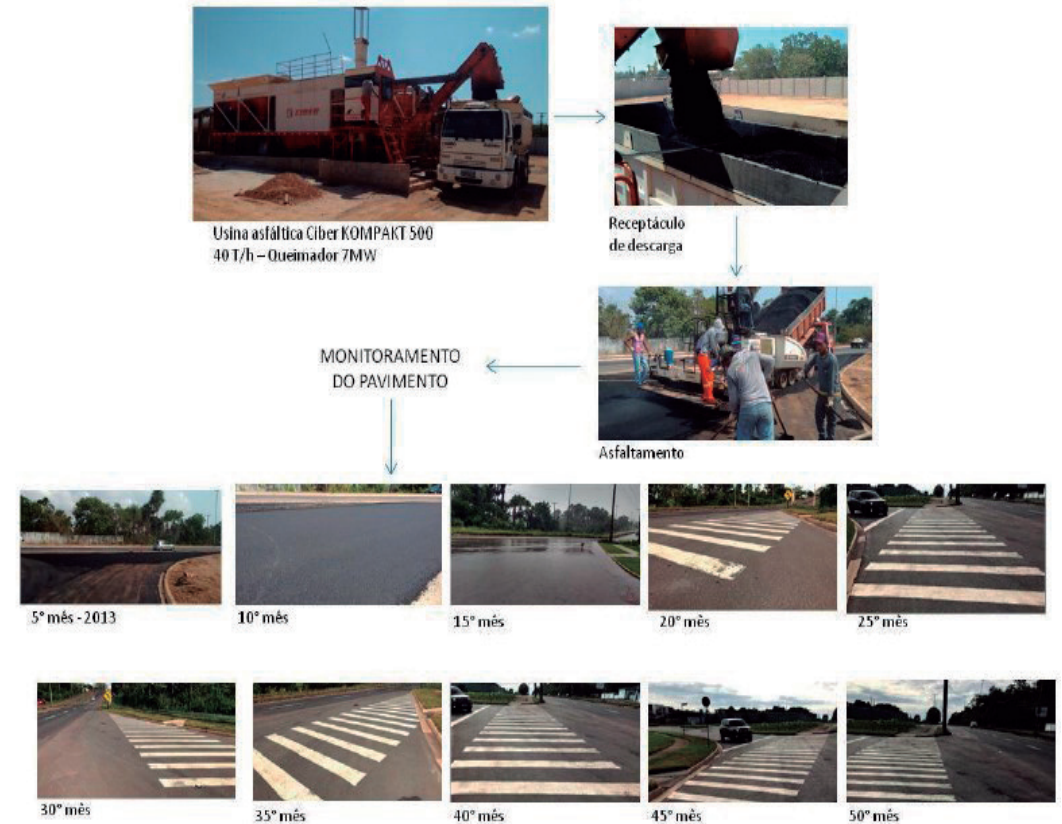

Fonte: elaborado pelos autores, 2021.

\section{LEGISLAÇÃO E O RCC}

O depósito inadequado dos resíduos da construção civil e de demolição compromete a paisagem do local, o tráfego de pedestres e de veículos e provoca o assoreamento de rios, córregos e lagos, bem como o entupimento da drenagem urbana, acarretando enchentes, além de servirem de pretexto para o descarte irregular de outros resíduos não inertes, propiciando o aparecimento e a multiplicação de vetores de doenças, pondo em risco a saúde da população vizinha (BRASIL, 2002).

Os municípios devem disciplinar a gestão dos resíduos tanto para os pequenos quanto para os grandes geradores, implantando equipamentos para a triagem dos resíduos, a reciclagem e o armazenamento para o uso futuro (aterros de resíduos da construção classe A). Esses equipamentos, públicos, privados ou 
em parceria entre governo e setor privado, permitem a criação de uma nova cadeia produtiva, transformando o resíduo em matéria-prima e gerando emprego e renda (SINDUSCON-SP, 2012).

Com relação à destinação final, a maioria dos municípios utiliza para esse fim áreas denominadas bota-fora, que normalmente são oferecidas para aterramento com o interesse de correção de topografia e comumente esgotamse rapidamente. Desta forma, deve-se fazer o levantamento dessas áreas, identificando o número de áreas de operação, os proprietários, o responsável pela operação — seja ele público ou privado —, o volume médio descartado mensalmente e a capacidade de vida útil (PINTO; GONZÁLES, 2005, p. 25; PIOVEZAN JÚNIOR, 2007).

A logística reversa, nestes casos, visa a dar uma destinação adequada aos resíduos que já esgotaram seu ciclo de vida e reinseri-los no mercado através da reciclagem ou do reúso. A inserção logística reversa na construção civil, embora seja ainda incipiente no Brasil, já é uma realidade para muitos outros países, pois se mostrou uma ferramenta importante para a redução dos impactos ambientais, do uso dos recursos naturais e do volume de resíduos descartados. Ademais, trata-se de um importante mecanismo de desenvolvimento social, econômico e sustentável, uma vez que favorece o surgimento de novos negócios, traz retorno financeiro para as empresas que aderem a ela e preserva o meio ambiente para as futuras gerações (FONSECA; MAINTINGUER, 2019; VITORINO et al., 2010, p. 2).

\section{CONCLUSÕES}

O estudo bibliográfico apresentou os problemas causados pelos resíduos descartados incorretamente no meio ambiente e os impactos ambientais gerados, devido à sua degradação demorada na natureza, prejudicial à saúde da sociedade.

Os impactos na indústria da construção civil podem ser significativamente reduzidos a partir das inovações tecnológicas e da ecoinovação em plantas de produção. Outra necessidade é que estejam, tanto na fase de projeto quanto na fase de execução, de acordo com os relatórios ambientais, EIA e RIMA, de forma que atendam a exigências de municípios e estados.

Um exemplo prático citado neste trabalho refere-se à incorporação do composto madeira/borracha no ligante betuminoso, via seca, aplicado em um trecho urbano em Macapá-AP. Os resultados foram significativos após a abertura da via; o trecho experimental tem 50 meses de uso. O concreto asfáltico com a incorporação de madeira/borracha pelo processo da via seca não apresentou dificuldades adicionais além das encontradas quando se executam 
revestimentos convencionais. A produção da mistura asfáltica do processo via seca é operacionalmente mais simples que o processo via úmida, quando a madeira/borracha é introduzida no ligante asfáltico e depois é misturada com os agregados. Além disso, tem o potencial de consumir maiores quantidades de borracha de pneus, se comparado com o processo da via úmida, resultando em um maior benefício ambiental.

Previstos na PNRS, os acordos setoriais são uma espécie de contrato entre poder público e fabricantes, importadores, distribuidores e comerciantes, com o objetivo de compartilhar a responsabilidade pelo ciclo de vida dos produtos. Já a logística reversa definida na PNRS é um instrumento de desenvolvimento econômico e social caracterizado por ações, procedimentos e meios destinados a viabilizar a coleta e a restituição de resíduos sólidos ao setor empresarial, ou seja, na prática, precisa ser alinhado entre órgãos públicos e privados para o bom reaproveitamento no ciclo produtivo ou outra destinação final ambientalmente adequada.

\section{REFERÊNCIAS}

ABRELPE. Panorama dos Resíduos Sólidos no Brasil. São Paulo: ABRELPE, 2020.

ALMEIDA, A. P.; MENDES, N. O. M.; LIMA, A. H. L. Asfalto-borracha: uma solução sustentável à mobilidade urbana da Rodovia do 40 Horas, Ananindeua, PA. In: ENCONTRO NACIONAL DE ENGENHARIA E DESENVOLVIMENTO SOCIAL, 15., 2018, Salvador. Anais [...]: Salvador: ENEDS, 2018. p. 1-10.

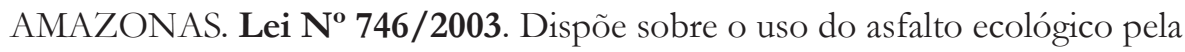
prefeitura de Manaus e dá outras providências. Manaus: Prefeitura Municipal de Manaus, [2003]. Disponível em: https://leismunicipais.com.br/a/am/m/ manaus/lei-ordinaria/2003/74/746/lei-ordinaria-n-746-2003-dispoe-sobre-ouso-do-asfalto-ecologico-pela-prefeitura-de-manaus-e-da-outras-providencias. Acesso em: 06 jun. 2020.

ARAVIND, K.; DAS, A. Pavement design with central plant hot-mix recycled asphalt mixes. Construction and Building Materials, [s. l.], v. 21, p. 928-936, 2007.

AZEVEDO, G. O. D.; KIPERSTOK, A.; MORAES, L. R. S. M. Resíduos da construção civil em Salvador: os caminhos para uma gestão sustentável. Eng. Sanit. Ambient., vol. 11, n. 1, 2006. 
BOSDOGIANNI, A. Municipal solid waste management in Greece legislation - implementation problems. In: INTERNATIONAL WASTE MANAGEMENT AND LANDFILL SYMPOSIUM, 11., 2007, Sardinia. Proceedings [...]. Sardinia: CISA, 2007. p. 1-10.

BRAGA, N. T. S.; GOUVEIA, M. S. Dialética da ocupação de áreas de várzea em Belém e propostas de drenagem compreensiva. Novos Cadernos NAEA, Belém, v. 23, n. 1, p. 243-260, 2020.

BRASIL. Lei $\mathbf{N}^{\mathbf{9}} \mathbf{9 . 6 0 5}$, de 12 de fevereiro de 1998. Dispõe sobre as sanções penais e administrativas derivadas de condutas e atividades lesivas ao meio ambiente [...]. Brasília, DF: Presidência da República, [1998]. Disponível em: http://www.planalto.gov.br/ccivil_03/leis/19605.htm. Acesso em: 03 jun. 2020. BRASIL. Lei $\mathbf{N}^{\mathbf{0}}$ 12.305, 02 de agosto de 2010. Política Nacional de Resíduos Sólidos; altera a Lei no 9.605, de 12 de fevereiro de 1998 [...]. Brasília, DF: Presidência da República, [2010]. Disponível em: http://www.planalto.gov.br/ ccivil_03/_ato2007-2010/2010/lei/112305.htm. Acesso em: 02 mar. 2020.

BRASIL. Ministério do Meio Ambiente. Conselho Nacional do Meio Ambiente. Resolução n 307, de 05 de julho de 2002. Estabelece diretrizes, critérios e procedimentos para a gestão dos resíduos da construção civil. Diário Oficial da República Federativa do Brasil, Brasília, DF, no 136, 17 de julho de 2002. Seção 1, p. 95-96.

BRASILEIRO, L. L.; MATOS, J. M. E. Revisão bibliográfica: reutilização de resíduos da construção e demolição na indústria da construção civil. Cerâmica, [s. l.], v. 61, n. 358, p. 178-189, 2015.

BRIBIÁN, I. Z.; CAPILLA, A. V.; USÓN, A. A. Life cycle assessment of building materials: Comparative analysis of energy and environmental impacts and evaluation of the eco-efficiency improvement potential. Building and Environment, [s. l.], v. 46, n. 5, p. 1133-1140, 2011.

BRUGNOLI, A. M.; NASCIMENTO, J. G. M.; MARQUES, C. S. A.; SILVA, G. R.; ORTIS, C. F. F. Análise de custo x benefícios na reciclagem de asfalto. In: CONGRESSO BRASILEIRO DE GESTÃO AMBIENTAL, 9., 2018, São Bernardo do Campo. Anais [...]. São Bernardo do Campo: CBGA, 2018. p. 1-11. CICLOSOFT. Pesquisa Ciclosoft. Ciclosoft, São Paulo, 2008. Disponível em: https:/ / cempre.org.br/wp-content/uploads/2020/08/Ciclosoft2008-Final.pdf. Acesso em: 08 abr. 2011. 
COELHO, J. G. M.; MESQUITA, A. L. A.; DIAS, C. G. B. Investigation of hardwood/rubber modified asphalt: Experimental track implementation in Macapá/AP. Case Studies in Construction Materials, [s. l.], v. 13, n. e00382, p. 1-12, 2020.

DEBONI, T. L.; SIMIONI, F. J.; ROSÁRIO, J. A.; COSTA, V. J. Quality of biomass from old wood waste deposits in Southern Brazil. Biomass and Bioenergy, [s. l.], v. 143, e105841, 2020.

DNER. DNER-ME 083/98: agregados - análise granulométrica. Rio de Janeiro: DNER, 1998.

DNIT. Manual de pavimentação. 3. ed. Rio de Janeiro: DNIT, 2006.

FAGUNDES, H. A. V.; HASELEIN, C. R.; BONIN, L. C. Redução de perdas e aproveitamento de resíduos para a produção de madeira serrada de melhor qualidade. In: ENCONTRO BRASILEIRO EM MADEIRAS E EM ESTRUTURAS DE MADEIRA, 10., 2006, São Pedro. Anais [...]. São Pedro: CEVEMAD/UNESP, 2006. p. 1-11.

FANG, C.; LI, T.; ZHANG, Z.; WANG, X. Combined Modification of Asphalt by Waste PE and Rubber. Polymer Composites, [s. l.], v. 29, n. 9, p. 1183-1187, 2008.

FEARNSIDE, P. M.; GRAÇA, P. M. L. A. BR-319: a rodovia Manaus-Porto Velho e o impacto potencial de conectar o arco de desmatamento à Amazônia central. Novos Cadernos NAEA, Belém, v. 12, n. 1, p. 19-50, 2009.

FONSECA, M. J. M.; MAINTINGUER, S. I. Aplicação da logística reversa na construção civil como mecanismo ambiental sustentável em políticas públicas. Brazilian Journal of Development, Curitiba, v. 5, n. 1, p. 140-149, 2019.

FRANCO, D. G. B.; STEINER, M. T. A. Optimization in waste landfilling partitioning in Parana State, Brazil. Journal of Cleaner Production, [s. l.], v. 283, e125353, 2021.

GALLE, A. H.; LOPES, E. F. S.; ARAÚJO, M. J. G.; GRAMA, Y. S. A influência do pneu no meio ambiente. In: SIMPÓSIO INTERNACIONAL DE CIÊNCIAS INTEGRADAS DA UNAERP CAMPUS GUARUJÁ, 1., 2010, Guarujá. Anais [...]. Guarujá: SICI, 2010. p. 1-13. 
GOU, F.; ZHANG, J.; PEI, J.; ZHOU, B.; FALCHETTO, A. C.; HU, Z. Investigating the interaction behavior between asphalt binder and rubber in rubber asphalt by molecular dynamics simulation. Construction and Building Materials, [s. l.], v. 252, p. 118956, 2020.

HAMMES, G.; SOUZA, E. D.; RODRIGUEZ, C. M. T.; MILLAN, R. H. R.; HERAZO, J. C. M. Evaluation of the reverse logistics performance in civil construction. Journal of Cleaner Production, [s. l.], v. 248, e119212, 2020.

JACOBI, P. Educação ambiental, cidadania e sustentabilidade. Cadernos de Pesquisa, São Paulo, v. 118, p. 189-205, 2003.

KARPINSKI, L. A.; PANDOLFO, A.; REINEHR, R.; GUIMARÃES, J.; PANDOLFO, L.; KUREK, J.; ROJAS, J. W. J. Gestão de resíduos da construção civil: uma abordagem prática no município de Passo Fundo/RS. Estudos Tecnológicos, São Leopoldo, v. 4, n. 2, p. 69-87, 2008.

KAZA, S.; YAO, L. C.; BHADA-TATA, P.; VAN WOERDEN, F. What a Waste 2.0: a Global Snapshot of Solid Waste Management to 2050. Washington, DC: World Bank, 2018.

LEÓN, C.; ROBLES, M. Developing a cadre of professional with a global environmental perspective. Ocean \& Coastal Management, [s. l.], v. 45, n. 9-10, p. 633-648, 2002.

MARTIN, E. J. P.; OLIVEIRA, D. S. B. L.; OLIVEIRA, L. S. B. L.; BEZERRA, B. S. Life cycle comparative assessment of pet bottle waste management options: A case study for the city of Bauru, Brazil. Waste Management, [s. l.], v. 119, p. 226-234, 2021.

MORAES, W. T.; SOLA, F. Extrafiscalidade ambiental: o estado do conhecimento no Brasil. Novos Cadernos NAEA, Belém, v. 22, n. 3, p. 157 $175,2019$.

OLIVEIRA, F. A.; MAUÉS, L. M. F.; ROSA, C. C. N.; SANTOS, D. G.; SEIXAS, R. M. Previsão da geração de resíduos na construção civil por meio da modelagem BIM. Ambiente Construído, Porto Alegre, v. 20, n. 4, p. 157-176, 2020.

PAIXÃO, F. J. M.; SILVA, M. L. A educação ambiental como política pública para gestão integrada dos recursos naturais: um estudo de caso do município de Paragominas no estado do Pará. Novos Cadernos NAEA, Belém, v. 22, n. 2 , p. 93-115, 2019. 
PEREIRA, A. F.; CARVALHO, L. S. C.; PINTO, A. C. O. Resíduo de madeira: limites e possibilidades de seu uso como matéria-prima alternativa. In: CONGRESSO BRASILEIRO DE PESQUISA E DESENVOLVIMENTO EM DESIGN, 9., 2010, São Paulo. Anais [...]. São Paulo: Blücher e Universidade Anhembi Morumbi, 2010. p. 1-10.

PETROBRAS. Asfalto: informações técnicas. Rio de Janeiro: Petrobras, 2015. PINTO, T. P. Gestão ambiental dos resíduos da construção civil: a experiência do SINDUSCON-SP. São Paulo: SINDUSCON, 2005. 47 p. PINTO, T. P.; GONZÁLES, J. L. R. (coord.). Manejo e gestão dos resíduos da construção civil: como implementar um sistema de manejo e gestão nos municípios. Brasília, DF: CAIXA, 2005. v. 1. 194 p.

PIOVEZAN JÚNIOR, G. T. A. Avaliação dos resíduos da construção civil (RCC) gerados No Munício de Santa Maria. 2007. Dissertação (Mestrado em Engenharia Civil) - Programa de Pós-Graduação em Engenharia Civil, Universidade Federal de Santa Maria, Santa Maria, 2007.

PRATICÒ, F. G.; AMMENDOLA, R.; MORO, A. Factors affecting the environmental impact of pavement wear. Transportation Research Part D, [s. l.], v. 15, n. 3, p. 127-133, 2010.

RAUBER, A. C. C.; CASSANEGO, M. L.; SILVA, R. F. Diagnóstico de impactos ambientais causado por usina de asfalto. Disciplinarum Scientia, Santa Maria, v. 5, n. 1, p. 97-106, 2004.

SANTA CATARINA. Lei No 18.145, de 29 de junho de 2021. Dispõe sobre o uso de asfalto adicionado com borracha proveniente da reciclagem de pneus inservíveis na conservação das estradas do Estado e vias municipais. Florianópolis: Assembleia Legislativa do Estado de Santa Catarina, [2021]. Disponível em: http://leis.alesc.sc.gov.br/html/2021/18145_2021_lei.html. Acesso em: 05 jul. 2021.

SANTANA, R. R.; SANTOS, R.; CAVALCANTE, E. H.; CARDOSO, G. Stability and adhesiveness of modified asphalt binder with oil sludge blend and tire rubber. Revista Matéria, Rio de Janeiro, v. 23, n. 1, p. 1-6, 2018.

SANTERO, N. J.; HARVEY, J.; HORVATH, A. Environmental policy for long-life pavements. Transportation Research Part D, [s. l.], v. 16, n. 2, p. 129-136, 2011. 
SANTOS, R. P.; TUBINO, R. Potential evaluation of the use of construction and demolition waste (CDW) in the recovery of degraded soils by mining in Brazil. Resources, Conservation \& Recycling Advances, [s. l.], v. 12, e200060, 2021.

SÃO GONÇALO. Lei $\mathbf{N}^{\mathbf{0}}$ 714, 21 de julho de 2017. Institui o programa de reciclagem de entulhos de construção civil e demolição no município de São Gonçalo, visando incentivar o reaproveitamento de materiais na construção civil para a promoção da construção sustentável, e dá outras providências. São Gonçalo: Prefeitura Municipal São Gonçalo, [2017]. Disponível em: https:/ / www.jusbrasil.com.br/diarios/154144773/dom-qsd-rj-21-07-2017-pg-1/ pdfView. Acesso em: 05 jun. 2020.

SÃO PAULO. Projeto de Lei $\mathbf{n}^{\mathbf{0}} \mathbf{1 . 5 0 0 , 2 0 0 7}$. Determina que as rodovias estaduais sejam pavimentadas e recapeadas com o asfalto-borracha (asfaltoecológico). São Paulo: Assembleia Legislativa do Estado de São Paulo, [2007]. Disponível em: https://www.al.sp.gov.br/propositura/?id=773812. Acesso em: 01 mar. 2020.

SERRA, G. A.; GUIMARÃES, A. C. R.; SILVEIRA, V. L.; BARROS, A. M. S.; REIS, A. C. C. Estudo da adição de resíduos de polietileno tereftalato (PET) como agregado alternativo para misturas asfálticas. In: CONGRESSO DE PESQUISA E ENSINO EM TRANSPORTES, 32., 2018, Gramado. Anais [...]. Gramado: ANPET, 2018. p. 1-13.

SHIH, H-C.; MA, H-W. Assessing the health risk of reuse of bottom ash in road paving. Chemosphere, [s. l.], v. 82, n. 11, p. 1556-1562, 2011.

SINDUSCON-SP. Resíduos da construção civil e o estado de São Paulo.

São Paulo: Secretaria do Meio Ambiente do Estado de São Paulo, 2012.

SOUZA, U. E. L.; PALIARI, J. C.; AGOPYAN, V.; ANDRADE, A. C. Diagnóstico e combate à geração de resíduos na produção de obras de construção de edifícios: uma abordagem progressiva. Ambiente Construído, Porto Alegre, v. 4, n. 4, p. 33-46, 2004.

STRAND, J.; SOARES-FILHO, B.; COSTA, M. H.; OLIVEIRA, U.; RIBEIRO, S. C.; PIRES, G. F.; OLIVEIRA, A.; RAJÃO, R.; MAY, P.; HOFF, R. V. D.; SIIKAMÄKI, J.; MOTTA, R. S.; TOMAN, M. Spatially explicit valuation of the Brazilian Amazon Forest's Ecosystem Services. Nature Sustainability, [s. l.], v. 1, p. 657-664, 2018. 
TAPKIN, S.; ÇEVIK, A.; UŞAR, Ü. Prediction of Marshall test results for polypropylene modified dense bituminous mixtures using neural networks. Expert Systems with Applications, [s. l.], v. 37, n. 6, p. 4660-4670, 2010. VITORINO, K. M. N.; CORREIA, J. C. D. A.; XAVIER, L. H.; FREIRE, N. Logística reversa e responsabilidade pós-consumo nas leis estaduais brasileiras para resíduos sólidos. In: SIMPOSIO IBEROAMERICANO DE INGENIERÍA DE RESIDUOS, 3., SEMINÁRIO DA REGIÃO NORDESTE SOBRE RESÍDUOS SÓLIDOS, 2., 2010, João Pessoa. Anais [...]. João Pessoa: REDISA-UFPB, 2010. p. 1-10. 